\title{
Escalating Health Care Cost due to Unnecessary Diagnostic Testing
}

\author{
MUHAMMAD AZAM ISHAQUE CHAUDHARY*, AND ASIM NISAR* \\ RECEIVED ON 12.05.2016 ACCEPTED ON 16.08.2016
}

\begin{abstract}
Focusing on health care systems can improve health outcomes now and in the future. Growing economies have serious concerns on the rising cost of health, whereas, in under developed countries like Pakistan, it is not emphasized yet at all. The research is conducted to improve a unique aspect of health care systems to provide effective, patient-centred, high-standard health care while maintaining the cost effectiveness. Research is being qualified in two paradigms qualitative and quantitative. In qualitative research, expert's interviews have been taken to get the basic knowledge of radiology based testing and their prerequisites, in quantitative research ordered are being analysed to check the frequency and if they are unnecessary or qualified medical necessity guidelines as established in qualitative method. Analysis was made on the basis of the trinity relationship of diagnosis, symptoms and respected order to determine the necessity of the order to get its impact on cost of the overall health of those patients and point out more than $50 \%$ unnecessary orders are being performed in two government hospitals. The situation is alarming and policy makers should focus on unnecessary ordering to avoid out of pocket expenses and improve quality of care. The research helps in successful application of health care system modifications and policies pertaining to one aspect of health systems, i.e. cost-effectiveness of health care.
\end{abstract}

Key Words: Cost-Effective, Health System, Radiology Orders.

\section{INTRODUCTION}

$\mathrm{H}$

uman minds have a limited ability to grasp and process multiple pieces of information simultaneously, but they desire to produce more to reap more benefits. A high level of productivity requires dropping the quantity/extent of information to be analyzed every time to only the most necessary and vital data. Developing a regular routine work in advance leads to the creation of frameworks, and sticking to it consistently wipes away the difficulty of thinking about what needs to be done, its sequence, and when and what resources are required. Health systems and health systems research leads to the creation of scaffold that must satisfy the demands and needs of its constantly dynamic building blocks. Health care is a management, treatment and prevention of disease or illness; it also refers to the physical well being through health service providers and hospitals. How are you? It is that simple question which is being asked by every two humans when they meet. This simply relates the concern of one to another about knowing his/her current physical,

* Department of Engineering Management, Center for Advanced Studies in Engineering, Islamabad.

Mehran University Research Journal of Engineering \& Technology, Volume 36, No. 3, July, 2017 [p-ISSN: 0254-7821, e-ISSN: 2413-7219] 
mental, financial and social status. We are concerned here about the physical and mental health of human beings that is one of the top concerns of humanity. Nowadays quality of care has become too expensive [1]. Not everyone can easily afford it. Health care expenditures are growing around the world in an alarming rate. The United States spends 17\% of their GDP (Gross Domestic Product). They are forecasted to reach 20.3\% of their GDP which equals to \$4.4 Trillion dollars [2]. OECD (Organization for Economic Cooperation and Development) countries average spending more than $7 \%$ of their GDP [3]. Such an alarming rise creates many risks for the sustainability of the future of health of the world. Now the question is where the health care cost goes? There are various ways to see health expenditures, although it is clear that cost may be increasing due to increasing cost of drugs and medicine, increasing rate of emergency to inpatient ratio, and excessive laboratory testing's [4]. Due to technological advancement doctors start relying on technology to diagnose problem and that increases the cost. Our focus is to highlight expensive laboratory testing in Pakistan and see if these are being ordered right with proper diagnosis along with chief complaint or if it is just a wastage of money and resources. Such research has never been conducted in Pakistan before that may help policymakers to establish certain policies pertaining to health systems to improve overall health of individuals along with decreased cost of care.

\section{LITERATURE REVIEW}

Pakistan is currently 6th most populous country with a population of more than 191 million people and an annual growth rate of $4 \%$ per annum. No satisfactory attention was given till the 1970's. Afterthat a 5 year plan was introduced to take care of infrastructural growth, but it was still limited to the government employees and the total spending was only $1 \%$ of the GDP. The rest was an out of pocket expense
[5]. According to WHO (World Health Organization), they defined Health as a state of absence of any disease and a complete wellbeing "physically and mentally" [6]. Health system is defined in several ways. "WHO's defines "Health Systems" as "All activities with the primary objective to promote reinstate or maintain health”. All such activities are usually grouped into six classes that include service delivery as well as, the health workforce, including health information system related Medical products, vaccines and technologies, health system financing and governance with right kind of leadership [7]. The another way of defining Health systems is based on the actors contributing to the system. Van Atteveld et. al. [8] reviewed 144 studies on health care and global health research. They concluded that most of the studies lacked analytical models mostly descriptive, economic approach dominated, and there were no comparison among different systems.

Alliance for health policy and system research studied and listed 41 health system frameworks developed till now [6] few have been developed for better knowledge, comparisons among different frameworks their performance [9].

Researchers believe that nowadays medicine has prompted communication among each other and different nations readily borrow ideas from another country's experiences. According to their own cultural setting they alter and modify ideas. But due to procedural variations among them and different structures of individual nations, developing an appropriate analytic framework that is good for everyone is yet to be done. There is no particular system or framework that covers all aspects of healthcare. The background of each healthcare system has its own dependence on several actors and environment which fails to create a basis for all [10]. Common health fund recently published a study by comparing 18 different health systems around the world but are still unable to provide any specific system that fits for all [11]. In a recent comparison of health care systems around the world, it was evident that caring needs are touching high

Mehran University Research Journal of Engineering \& Technology, Volume 36, No. 3, July, 2017 [p-ISSN: 0254-7821, e-ISSN: 2413-7219] 
expectations and viz a viz cost containment is also required including laboratory services for a sustainable growth in health care services [12].

The question frequently raised in health policy debates is, "Will health systems be financially sustainable in future?” It is usually termed as the ability of the governments and others to sufficiently finance health care in the face of growing cost pressures, with the following three most commonly cited challenges named as population ageing, innovation or new technologies and quality of care which is consumer expectations around the world. Although the idea of 'financial sustainability' comes into view to be vital to health policy debates, but still it has not been part of most health system objectives, including those of the WHO's health system performance framework" [6].

The problem of financial sustainability can be broadly characterized in the following three ways which includes increased health expenditure due to demand and supply of health services, technological progress, demographic changes and consumer expectations. Some believe limited resources or an inability of government or unwillingness to generate sufficient resources to meet its health system obligations which might be due to financial crisis [13]. Substantial research has been done by different institutes and researchers on why health care costs are raising across the globe. The factors that get most attention are connected with the increasing volume of services used. These include the following parameters coupled with rising income and expectations are technology advancement, population ageing and changing utilization patterns. Although it depends upon country as per their clinical setting, operating methods, and specific case evaluated, studies have evidently reported that up to $40 \%$ of lab testing can be considered as wasteful [14-17].

It is evident from the analysis and projections that the population ageing contributes comparatively less to rising health care costs in comparison to technological modernization (10\% less of the growth in health care costs) [18-20]. Health care expenditures are rising in at alarming rate. Advancement in technology is one of the key factors in raising heath care cost which is laboratory orders [21]. From 2005-2010 it is evident that laboratory testing cost increased by $29 \%$ of the total health care cost in United States [22]. Fig. 1 shows Health expenditures as a share of GDP of OECD countries.

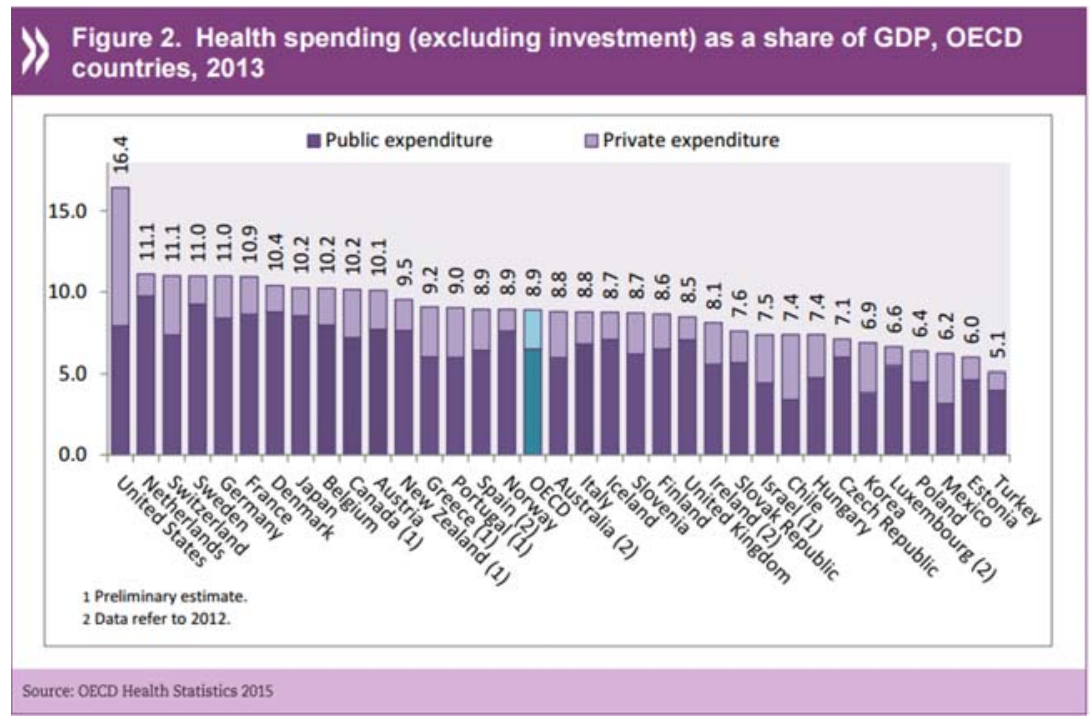

FIG. 1. HEALTH EXPENDITURE AS A SHARE OF GDP OECD COUNTRIES 2015 [23] 
Getting quality of care is the right of every human in this world but nowadays cost of health care is becoming a raising issue as quality of care is directly proportional to the cost of health care. This relationship forced policy makers, and researchers to devise a strategy of lowering the costs. Now some suggest to see health care professionals other than doctors, and put emphasis on telemedicine, and believe that a cure is better than care [24].

Because of rising healthcare costs, USA took few steps to control the rising cost of healthcare. Successful efforts were made for the mandatory use of electronic health records, along with introducing physicians quality reporting system, and creating medical necessity policies as to check and perform an analysis whether the service is planned to deliver medically required/ necessary for the patient or it is not required. Emanuel elaborates that simply by reducing avoidable health complications, there could be more than $10 \%$ of saving per year [25].

\section{RESEARCH GAP}

Currently top spending nations are following utilization pattern to regulate care needs and see whether the service is required or not. This concluded to be creating local coverage policies, but it happens when some specific area or people start providing that kind of services. There is a requirement to check and analyze the patterns on laboratory orders and specifically high cost orders that are made to contain cost in health care. This research specifically focuses on Pakistan to check if unnecessary tests have been ordered as compare to the rest of the world and devise a strategy to stop unnecessary testing and create check and balance to reduce wastage of money and resources.

\section{RESEARCH METHODOLOGY AND DATAANALYSIS}

Research is being qualified in two paradigms qualitative and quantitative. In qualitative research, expert's interviews have been taken to get the basic knowledge of radiology based testing and their prerequisites. Question were being asked with respect to the specialty and create a basic understanding of why imaging orders have been placed and study all those procedures in which medical decision making are involved. Research methodology of the paper is be described as shown in Fig. 2.

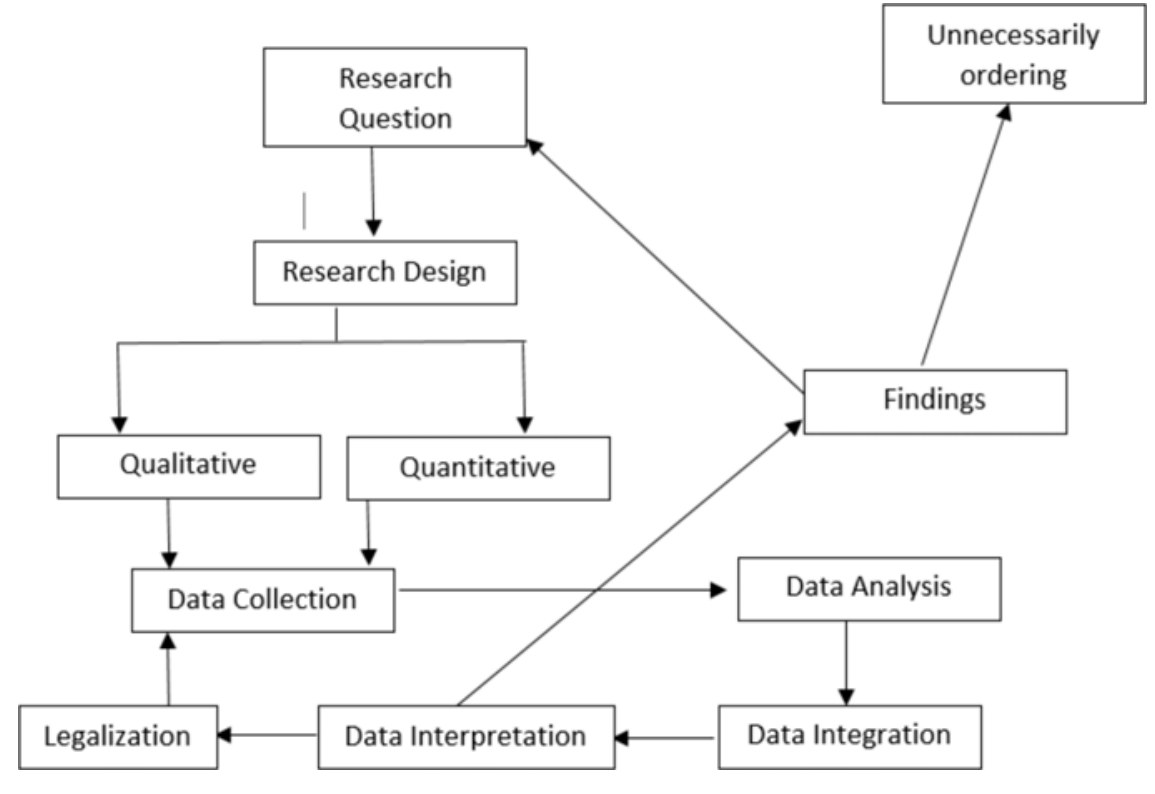

FIG. 2. RESEARCH METHODOLOGY FLOW DIAGRAM

Mehran University Research Journal of Engineering \& Technology, Volume 36, No. 3, July, 2017 [p-ISSN: 0254-7821, e-ISSN: 2413-7219] 
We initiated the research with a simple question that whether in Pakistan the radiology orderings are based on medical necessity or not? In order to get the answer of the question the research methodology selected was qualitative and quantitative. The qualitative research was conducted through interviewing physicians about the radiology orderings and its basics that can be seen from Fig. 3. The quantitative research helped us to compile relevant and specific data and analyze it for findings that can be seen from Fig. 4.

On the basis of qualitative research, quantitative research was carried out in which retrospective data of radiology investigation was collected for six months from two reputed government hospitals of Islamabad and Rawalpindi. Methodology used to understand and investigate the domain and problem respectively is shown in Fig. 3.
Light blue ordering techniques were selected as primary source of investigation because of the fact that these are most ordered procedures are costly as well.

After qualitative research data collection was carried out to investigate whether unnecessary tests was being ordered or not. This methodology is described as shown in Fig. 4.

The underlined research methodology helped us to gather data pertaining to the distinct radiology orders. Total number of orders which had considerable information documented were 2395.All the imaging studies were being ordered by different physicians including x-ray, ultrasound, MRI (Magnetic Resonance Imaging) and CT (Computed Tomography) scan and other laboratory orders but only MRI and CT scan were included in this study. These radiology orders were charted on the basis of cost as these were the

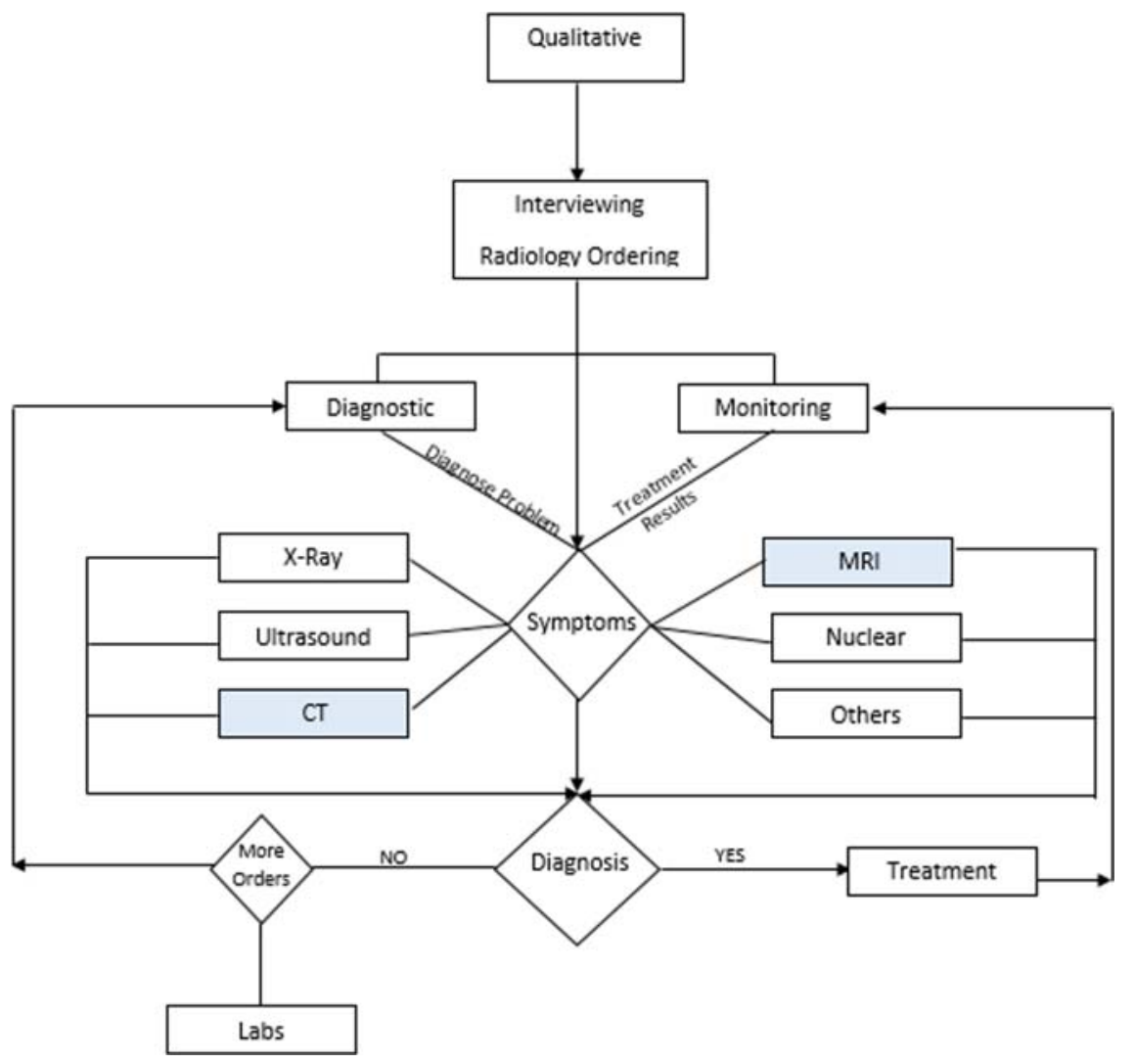

FIG. 3. QUALITATIVE METHOD FLOW DIAGRAM

Mehran University Research Journal of Engineering \& Technology, Volume 36, No. 3, July, 2017 [p-ISSN: 0254-7821, e-ISSN: 2413-7219] 
most expensive laboratory diagnostic orders. First total number of MRI and CT scan were identified other than emergency patients. Only inpatient and outpatient facility were taken in this study. The reasons of prescribing MRI/ CT scan were identified. Analysis was made and following were the results. Table 1 shows total MRI/ CT scan stats.

Data shows that CT scans were ordered more on female whereas more MRI ordered on males. Total 166 MRI/CT Scan orders were analyzed. These are all being ordered in outpatient and inpatient facility. None of the order were based on monitoring was analyzed. Then analysis were made on the basis of symptomology in each gender as shown in Table 2 to identify reason of unnecessary orders.

Table 2 shows diagnosis/complaints on which various orders have been made, but out of 166 orders data, showed that 99 orders were placed due to user defined complaints without prior physician's clinical evaluation to justify the test requirement and medical necessity. Although very less document evident exists, at the time of order reason were not clearly written or identified. Rest 67 orders have rational of being prescribed.

\section{RESULTS}

Most of conclusion/findings of the study showed normal study which creates an alarming situation and proof the concept of unnecessary orders have been performed in Pakistan as well. As stated above, researchers believe $40 \%$ of laboratory testing is unnecessary but in case of Pakistan data shows more than $50 \%$ of testing is unnecessary. As shown in Fig. 5, data showed that out of 166 studies, 77 studies findings were normal and 17 findings were unknown because of some technical issue or tests not performed well. According to experts these 77 studies which ere found normal can be further reduced by careful clinical examination.

As shown in Fig. 6 maximum number of orders have been made on user defined complaints. During interviews most doctors said that when pateints vist them in service doctor most of them answered as patient visit us in severe painan order of MRI and or CT scan was most commonly ordered.

TABLE 1. MRI/CT SCAN ORDERED STUDIED

\begin{tabular}{|c|c|c|c|}
\hline Gender & CT Scan & MRI & Total \\
\hline Female & 58 & 26 & 84 \\
\hline Male & 42 & 40 & 82 \\
\hline Grand Total & 100 & 66 & 166 \\
\hline
\end{tabular}

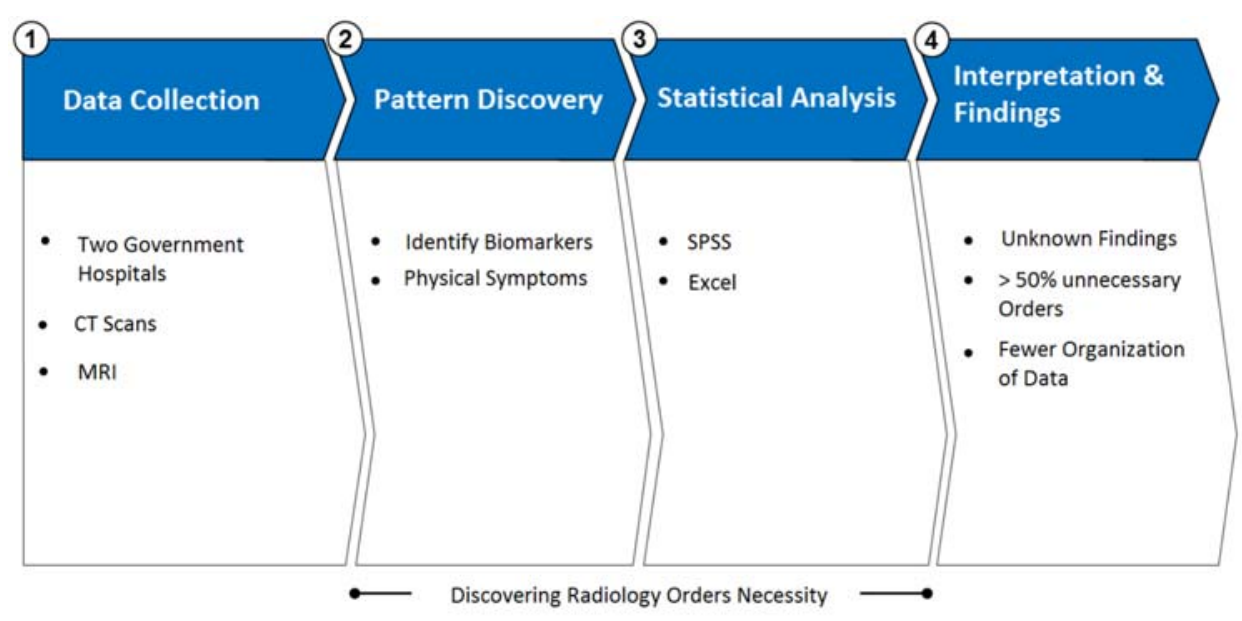

FIG. 4. QUANTITATIVE METHOD FLOW DIAGRAM 
From Figs. 5-6 results shows that more than $50 \%$ of the diagnostic orders made were unnecessary (combining the normal findings and unknown findings together), this all adds extra burden to financial cost. Country like Pakistan if we analyze last seven years i.e. (since 2007-2008 Rs. 60 billion to 2013-2014 Rs. 102 billion) have been allocated for the health sector, which is merely equal to $1 \%$ of their GDP. Recently Government of Pakistan has also allocated Rs. 2/- Billion under Prime Minister National Health Program to become a welfare state without having any policies in place and check and monitoring of quality of care. By analyzing above findings there is a need of expert system be designed to formulate policies to stop unnecessary testing and save cost. Orders should be prescribed as per medical necessity guidelines and if proper documentation and history of the patient formulates the basis of order then test should be performed, otherwise it should be referred to the review process. This way unnecessary radiation exposure can be reduce and out of pocket expenses can also be minimized.

\section{RESEARCH LIMITATIONS}

Medical necessity applies to all aspects of practicing medicine but the scope of this research limits its boundaries by focusing only on medical necessity of imaging orders.

TABLE 2. MRI/CT SCAN ORDER DIAGNOSIS DETAILS

\begin{tabular}{|c|c|c|c|c|}
\hline Gender & Symptoms & $\mathrm{CT}$ & MRI & Total \\
\hline \multirow{11}{*}{ Female } & Backache & 20 & 1 & 21 \\
\hline & Diminished vision & 1 & & 1 \\
\hline & Dizziness & 2 & 1 & 3 \\
\hline & Headache & 2 & 1 & 3 \\
\hline & Joint pain & 7 & 1 & 8 \\
\hline & Pain in Lumbar Area & 2 & & 2 \\
\hline & Rash & & 1 & 1 \\
\hline & Shortness of Breath & 1 & & 1 \\
\hline & Urinary Problems & 2 & & 2 \\
\hline & User Defined Complaint & 21 & 20 & 41 \\
\hline & Not Mentioned & & 1 & 1 \\
\hline \multicolumn{2}{|r|}{ Female Total } & 58 & 26 & 84 \\
\hline \multirow{9}{*}{ Male } & Backache & 07 & 08 & 15 \\
\hline & Constipation & 1 & & 1 \\
\hline & Cough & 0 & & 0 \\
\hline & Dizziness & 2 & & 2 \\
\hline & Pain In Hand & & 1 & 1 \\
\hline & Trauma & & 1 & 1 \\
\hline & User Defined Complaint & 31 & 27 & 58 \\
\hline & Weakness & 1 & & 1 \\
\hline & Not Mentioned & & 3 & 3 \\
\hline \multicolumn{2}{|r|}{ Male Total } & 42 & 40 & 82 \\
\hline
\end{tabular}

Mehran University Research Journal of Engineering \& Technology, Volume 36, No. 3, July, 2017 [p-ISSN: 0254-7821, e-ISSN: 2413-7219] 


\section{Order Categories}

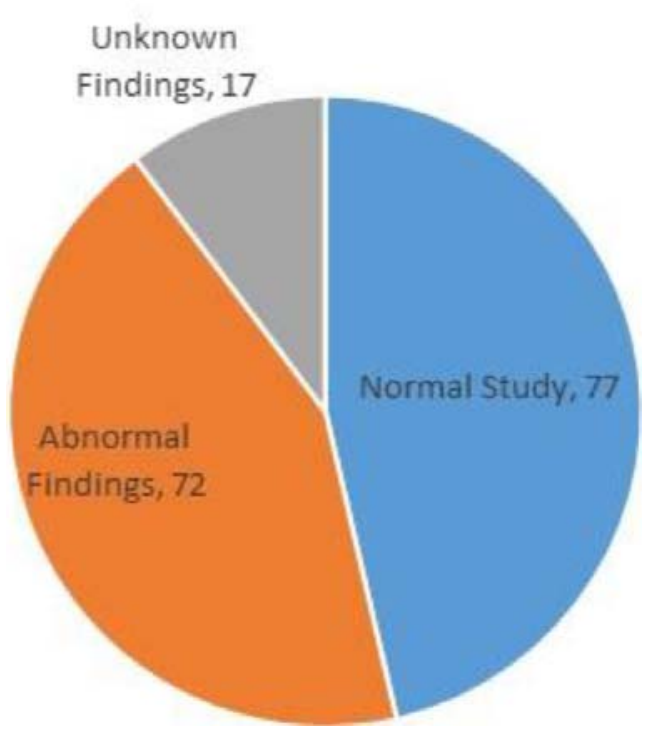

FIG. 5. MRI/ CT SCAN RESULTS FINDINGS

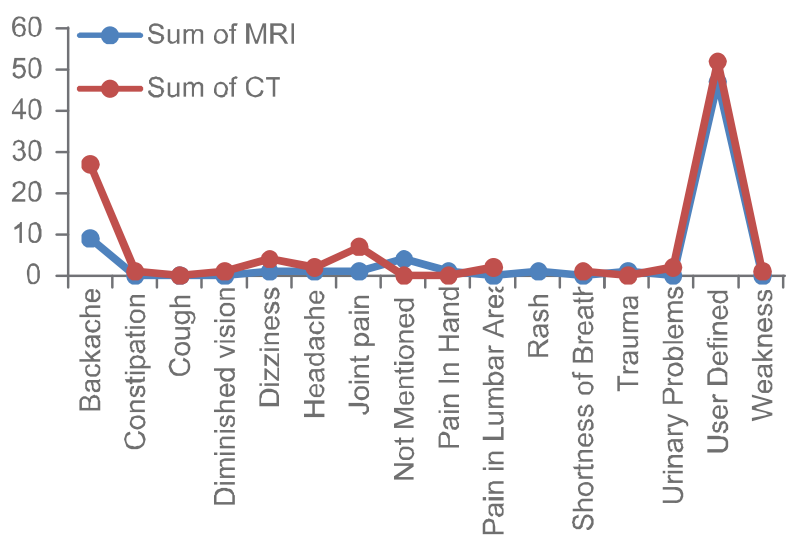

FIG. 6. SYMPTOMOLOGY GRAPH W.R.T MRI AND CT SCAN ORDERS

\section{CONCLUSIONS}

The rapid growth in the medical sciences has kept things difficult for the human beings to cope up with the changing domain knowledge. From very basic of surgery to basic body checkup, medical practices have taken a new turn. The core reason is the ongoing research throughout the world that is adding valuable information about human body. With the changing medical practices, it is imperative that the associated procedures must also evolve. There are various phases of evolution that have taken place in medical practices, however, the need of a standardized medical practice has still remained a key challenge. In earlier days, physicians generally relied on the physical check up to determine the root cause of any disease. With the advancement in technology and availability of modern day equipment, the reliance has generally reduced on physical checkups. Rather all the physicians generally rely on medical tests for determining the root cause of a disease. This research opens a new era of cost containment in health care industry. Policy makers and healthcare financial analysts will get benefited from it to lower down the cost of providing care by developing knowledge base decision support system. Health care insurances will also get benefited from the research to evaluate the healthcare claims. This is one of the biggest reason that no insurances are covering health care benefits as without check and balance, anyone can order any kind of expensive or inexpensive testing without documenting a proper diagnosis. More than $50 \%$ of orders that have been made will be an eye opening situation for the policy holders. Any test that have been ordered must comply medical necessity guidelines, and be placed after clinical examination which will reduce unnecessary exposure to the radiations and healthcare cost. Experts have the opinion that a clinical perspective of medical necessity is very rare, it merely goes with the organizational culture desire and most often influenced by the physicians and lied in the health care compliance context. It is very important here to understand that if a service rendered to a patient that is not medically demanded, it can save money if some framework or policies have been implemented to monitor the care delivery process. Cost effectiveness of the health care system needs to be prioritized throughout the world, especially in developing countries like Pakistan, where more than $50 \%$ of people are below the poverty line. 
Morbidity and mortality rate can be reduced by emphasizing on treatment rather than unnecessary investigation.

\section{FUTURE RESEARCH}

Future research can be carried out on unnecessary prescription and other laboratory orders to improve health care in Pakistan and decrease cost of care. Such research analysis forms the basis for policy makers to design effective policies for better health care.

\section{ACKNOWLEDGEMENTS}

Authors are highly thankful to Higher Education Commission of Pakistan, for the provision of scholarship for higher education and research. Authors are grateful to anonymous reviewers, for reviewing the paper along with editorial board and providing valuable feedback. Authors also acknowledge the hospitals and doctors who shared clinical data and played a key role to successfully complete this research.

\section{REFERENCES}

Blomqvist, A.G., and Carter, R.A.L., "Is Health Care Really a Luxury?”, Journal of Health Economics, Volume 16, No. 2, pp. 207-229, April, 1997.

Sisko, A., Truffer, C., Smith, S., Keehan, S., Cylus, J., and Poisal, J.A., "Health Spending Projections Through 2018: Recession Effects add Uncertainty to the Outlook", Health Affairs, Volume 28, No. 2, pp. 346-357, March, 2009.

Vandersteegen, T., Marneffe, W., Cleemput, I., and Vereeck, L., "The Impact of No-Fault Compensation on Health Care Expenditures: An Empirical Study of OECD Countries”, Health Policy, Volume 119, No. 3, pp. 367-374, March, 2015.

[4] Muennig, P., and Mark, B., "Cost-Effectiveness Analysis in Health: A Practical Approach”, John Wiley \& Sons, 2016.
[5] Mashhadi, S.F., Hamid, S., Roshan, R., and Fawad, A., "Healthcare in Pakistan-A Systems Perspective", Pakistan Armed Forces Medical Journal, Volume 66, No. 1, pp. 136-142, 2016.

[6] WHO, “The World Health Report 2000: Health Systems: Improving Performance”, World Health Organization, 2000.

[7] WHO, “The Tallinn Charter: Health Systems for Health and Wealth”, WHO, Regional Office for Europe, 2008.

[8] Van Atteveld, L., Broeders, C., and Lapre, R., "International Comparative Research in Health Care: A Study of the Literature”, Volume 8, No. 1, pp. 105-136, August, 1987.

[9] Hoffman, S.J., Rottingen, J.A., Bennett, S., Lavis, J., Edge, J., and Frenk, J., "A Review of Conceptual Barriers and Opportunities Facing Health Systems Research to Inform a Strategy from the World Health Organization”, WHO, 2012.

[10] Mechanic, D., and Rochefort, D.A., "Comparative Medical Systems", Annual Review of Sociology, Volume 22, No. 1, pp. 239-270, 1996.

[11] Elias, M., Wenzl, M., Osborn, R., and Sarnak, D., “2015 International Profiles of Health Care Systems”, The Commonwealth Fund, 2016.

[12] Lawall, K., "A Comparison of Health Care Systems in the Western World”, Theses and Dissertations, May, 2016.

[13] Ulf-G, G., and Jonsson, B., "International Comparisons of Health Expenditure: Theory, Data and Econometric Analysis”, Volume 1, Part A-B, Handbook of Health Economics, Ed. Elsevier, pp. 11-53, 2000.

[14] Baird, G., "The Laboratory Test Utilization Management Toolbox”, Biochemia Medica, Volume 24, No. 2, pp. 223-234, 2014.

[15] Bates M.D., David, W., Boyle, D.L., Rittenberg, M.A.E., Kuperman, M.D.P., Gilad, J., Ma’Luf, N., and Menkin B.A.V., "What Proportion of Common Diagnostic Tests Appear Redundant?”, The American Journal of Medicine, Volume 104, No. 4, pp. 361-368, April, 1998. 
[16] Huck, A., and Lewandrowski, K., "Utilization Management in the Clinical Laboratory: An Introduction and Overview of the Literature", Clinica Chimica Acta, Volume 427, pp. 111-117, January, 2014.

[17] McConnell, T.S., Berger, P.R., Dayton, H.H., Umland, B.E., and Skipper, B.E., "Professional Review of Laboratory Utilization”, Human Pathology, Volume 13, No. 4, pp. 399-403, April, 1982.

[18] Cutler, D.M., and McClellan, M., "Is Technological Change in Medicine Worth It?”, Health Affairs, Volume 20, No. 5, pp. 11-29, September, 2001.

Dormont, B., Grignon, M., and Huber, H., "Health Expenditure Growth: Reassessing the Threat of Ageing”, Health Economics, Volume 15, No. 9, pp. 947-963, 2006.

Seshamani, M., and Gray, A., "Time to Death and Health Expenditure: An Improved Model for the Impact of Demographic Change on Health Care Costs”, Age and Ageing, Volume 33, No. 6, pp. 556-561, 2004.
[21] Kim, J.Y., Dzik, W.H., Dighe, A.S., and Lewandrowski, K.B., "Utilization Management in a Large Urban Academic Medical Center”, American Journal of Clinical Pathology, Volume 135, No. 1, pp. 108-118, January, 2011.

[22] "Questionable Billing for Medicare Part-B Clinical Laboratory Services Report (OEI-03-11-00730) 07-082014" [Online]. Available: http://oig.hhs.gov/oei/reports/ oei-03-11-00730.asp. (Last Assessed on Mar 03, 2016).

[23] OECD, "Focus on Health Spending's OECD Health Statistics 2015", Organization for Economic Cooperation and Development, 2015.

[24] Mason, J., Freemantle, N., Nazareth, I., Eccles, M., Haines, A., and Drummond, M., "When Is It CostEffective to Change the Behavior of Health Professionals?”, Journal of the American Medical Association, Volume 286, No. 23, pp. 2988-2992, December, 2001.

[25] Emanuel, E.J., "Where are the Health Care Cost Savings?”, Journal of the American Medical Association, Volume 307, No. 1, pp. 39-40, January, 2012. 